\title{
Study on the Hydrodesulfurization Catalyst of Residual Fuel (Part 4)
}

\author{
- Improvement of Catalyst Support* \\ by Masao Inoguchi*1, Kazuhito Tate*2, Yoshito Kaneko*3, Yoshihito Satomi*4, \\ Kiyohiko Inaba*5, Takehiko Mizutori*6, Harumi Kagaya*7, \\ Reijiro Nishiyama*8, Saburo Onishi*9 and Tamotsu Nagai*10
}

\begin{abstract}
Summary: The control methods of pore properties of catalyst supports and the manufacturing methods of their desirable pore size distribution for hydrodesulfurization catalyst of residual fuel were studied. Namel], the correlations between pore properties of $\gamma$-alumina and preparation and calcination condition of alumina hydrates, especially boehmite gel, were investigated. From the experimental results, the following were obtained.

1) Itith higher hydrolysis temperature, the orystallites became larger, the specific surface area decreased and the pore volume of the pore having diameter less than $600 \AA$ increased. It hen aging period of boehmite gel was prolonged, the degree of cryslallinily advanced along with the crystal groweth of bayerite and consequently, the specific surface area and the pore volume decreased.

2) When the alumina hydrates were washed in water, the pore volume and the specific surface area decreased. When they were washed in alcohol, the pore volume and the specific surface area increased on the contrary.

3) As the calcination temperature was raised higher, the specific surface area decreased and, in reverse, the pore volume increased.

4) The most important effect on the pore structure of the alumina as catalyst support was the permeation of alcohols into the interstice of cry'stallites of alumina. 11 lso, selecting the preparation conditions of alumina hydrates adequately, the diameter of crystallites could be changed markedly. and, consequently, the pore structure could be controlled.

5) When the suitable kind of acid was added to alumina hydrates and they were calcined to make alumina supports, the specific surface area was constant independent of the acid concentration, while the pore volume and the mean pore diameter decreased according to increase of the acid concentration.
\end{abstract}

\section{Introduction}

In connection with the activity of hydrodesulfurization catalysts for residual fuel, kinds of

* Received July 3, 1971.

The study was carried out by Research and Development Association of Residual Fuel Hydrodesulfurization.

*1 Central Research Laboratory, Showa Oil Co., Ltd. (1-2-22, Ariake, Koto-ku, Tokyo, Japan)

*2 Research Laboratory, Mitsubishi Oil Co., Ltd.

*3 Central Research Laboratory, Toa Nenryo Kogyo K. $\mathrm{K}$.

*4 Central Research Laboratory, Nippon Mining (is.. Ltd.

*5 Production \& Refinery Co-ordination Dept., Daikyo Oil Co., Ltd.

*6 Research Section of Kawasaki Refinery, Asia Oil Co., Ltd.

*7 Research Section of Kawasaki Refinery, Toa Oil Co., Ltd.

*8 Research Laboratory of Osaka Refinery, Koa Oil Co., Ltd.

*9 Central Research Laboratory, Maruzen Oil Cio., Ltd.

*10 Research Section of Kawasaki Refincry, General Oil Refining Co., Ltd. catalysts, their physical properties and preparation methods had been studied from various viewpoints 1) -3). In consequence, it became clear that physical properties of catalysts, especially pore properties such as pore size distribution, pore volume and mean pore diametcr governed greatly the activity and selectivity of desulfurization reaction. For the purpose of controlling pore properties of the supports, the authors investigated preparation methods of the supports from alumina hydrates which were obtained by hydrolysis of aluminum alcoholatc. It is well known that the inorganic powder as alumina etc. possesses the structure sensitive property. For instance, its physical properties are remarkably variable depending on raw materials, impurities, conditions of hydrolysis, conditions of after-treatment of alumina hydrates etc..

In case of alumina, many papers ${ }^{4}$ have dealt with preparation methods and physical properties of alumina hydrates and phase transformation of alumina hydrates and alumina. Also de 
Boer $^{5), 6)}$ and Johnson?) reported about the effects of kinds of raw materials of alumina hydrates on pore size distribution. However, calcination condition of alumina hydrates etc., the correlations among pore properties of $\gamma$-alumina and, preparation methods of alumina hydrates, especially boehmite gel and, moreover, calcination conditions had not been studied sufficiently.

The authors investigated the methods to control the pore properties and also studied to obtain the supports whose large amount of pore was from $100 \AA$ to $200 \AA$ in diameter which would be appropriate for desulfurization catalyst support for residual fuel. Using alumina hydrates prepared by hydrolysis of aluminum isopropoxide and commercial alumina hydrates, we investigated the effects on supports of the following conditions: hydrolysis temperature, aging hour, aging temperature, washing conditions, drying and calcination temperature and period.

In this paper, the authors will describe the information derived from the above-mentioned investigation.

\section{Experiments}

\subsection{Preparation of samples}

Powder of commercial aluminum isopropoxide was further ground by the agate mortar into that of 50 to 100 mesh. $100 \mathrm{~g}$ of it was added into pure water of $300 \mathrm{ml}$, kept at a designated temperature for 10 minutes under stirring and left as it was for 30 minutes and then was stirred up well to complete hydrolysis. Further, it was aged under a given set of conditions and the precipitate was filtered and washed in 100 $\mathrm{ml}$ of isopropylalcohol to remove non-reacted materials. The alumina hydrates thus prepared was washed, dried and calcined under the designated conditons to make them suitable for measurements. Commercial alumina hydrate was one of the by-product when high molecular alcohol was made from tri-ethylaluminum (alfol aluminum). Observed impurities were as follows; $\mathrm{SiO}_{2} \quad 0.01 \quad w \mathrm{t} \%$ and $\mathrm{Na}_{2} \mathrm{O} \quad 0.01 \quad w t \%$. The type of crystallinity was observed to be the same as that of boehmite by means of X-ray diffraction.

\subsection{Measurement of Pore Properties}

Measurement of specific surface area was made using the BET Method based on the adsorption of $\mathrm{N}_{2}$, As for pore size distribution, we investigated the adsorption isotherm of liq. $\mathrm{N}_{2}$ at the boiling point $-196^{\circ} \mathrm{C}$ and calculated the pore size distribution of pores having a diameter less than $300 \AA$ using the method of Cranston and Inkley ${ }^{8}$. From the relative pressure of 0.967 , we determined the volume of the pores whose diameters were below $600 \AA$. The mean pore diameter was calculated from the following equation.

$$
D(\AA)=\frac{\text { Pore volume }(\mathrm{m} l / \mathrm{g})}{\text { Specific surface area }\left(\mathrm{m}^{2} / \mathrm{g}\right)} \times 4 \times 10^{4}
$$

\section{Results and Discussion}

\subsection{Effects of Hydrolysis Temperature and Aging Temperature}

Each $100 \mathrm{~g}$ of powder of aluminum isopropoxide was added into $300 \mathrm{ml}$ of pure water of (a) $43^{\circ} \mathrm{C}$, (b) $60^{\circ} \mathrm{C}$, (c) $85^{\circ} \mathrm{C}$ for the duration of 10 minutes with stirring for the while, and was hydrolysed. The alumina hydrates thus prepared were washed three times in $100 \mathrm{~m} l$ of isopropyl alcohol, dried at $120^{\circ} \mathrm{C}$ for 24 hours and calcined at $550^{\circ} \mathrm{C}$ in the air. The pore properties of the alumina were measured. The results are shown in Table 1 (1). As seen in the Table, when the temperature of hydrolysis was high, specific surface area decreased. The pore volume indicated the largest figure when hydrolysis was carried out at $60^{\circ} \mathrm{C}$. From this result, the following was observed: with higher hydrolysis temperature, crystallites grew larger and the specific surface area decreased. However, at the same time, pore volume of the pore having diameter less than $600 \AA$, though growing large accompanying the growth of crystallites, became small by sintering when the growth attained a certain degree and the large pores were supposed to be concentrated to a small number.

Then, to check the effects of aging, samples prepared by hydrolysis in pure water of $60^{\circ} \mathrm{C}$, were aged for (a) 0 hour, (b) 5 hours, and (c) 24 hours separately. The alumina hydrates thus manufactured were turned to $\gamma$-alumina by the following treatment and their pore properties were measured. The results are shown on Table 1 (2). From the above experimental results, the longer the aging time, the growth of bayerite proceeded in parallel with the growth of crystallinity of boehmite. This is supposed to be the reason that the specific surface area, pore volume etc. decreased.

\subsection{Effects of Drying Conditions}

Using the manufactured samples by hydrolysis of aluminum isopropoxide in pure water of $43^{\circ} \mathrm{C}$, the effects of drying conditions on physical properties were studied. As for the effects of drying temperatures, the samples were dried in muffle furnace controlled at $80^{\circ} \mathrm{C}, 100^{\circ} \mathrm{C}$, $120^{\circ} \mathrm{C}$ and $140^{\circ} \mathrm{C}$, for 24 hours and the decrease rate in volume was measured. As it was assured that desorption of adsorbed water of the samples was almost complete and their weight became constant by drying at $120^{\circ} \mathrm{C}$, for 24 hours, the effects of drying time on physical 
Table 1 Effects of Preparation Conditions on Physical Properties of Carrier

\begin{tabular}{|c|c|c|c|c|c|c|c|c|c|c|c|c|c|}
\hline \multirow{3}{*}{$\begin{array}{l}\vdots \\
\text { Sample } \\
\text { Number }\end{array}$} & \multicolumn{2}{|l|}{ 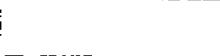 } & \multicolumn{6}{|c|}{ Preparation Conditions } & \multicolumn{3}{|c|}{ Pore Properties } & \multicolumn{2}{|l|}{ Crystallite } \\
\hline & & Aging & \multicolumn{2}{|c|}{ Washing } & \multicolumn{2}{|c|}{ Drying } & \multicolumn{2}{|c|}{ Calcining } & \multirow{2}{*}{$\begin{array}{c}\text { Surface } \\
\text { Area } \\
\left(\mathrm{m}^{2} / \mathrm{g}\right)\end{array}$} & \multirow{2}{*}{$\begin{array}{c}\text { Pore } \\
\text { Volume } \\
(\mathrm{m} / / \mathrm{g})\end{array}$} & \multirow{2}{*}{$\begin{array}{l}\text { Mecn } \\
\text { PoreDia- } \\
\mid \begin{array}{c}\text { meter } \\
(\AA)\end{array}\end{array}$} & \multirow{2}{*}{$\begin{array}{l}S i z e^{* * *} \\
d_{020} \\
(\AA)\end{array}$} & \multirow[t]{2}{*}{$\begin{array}{c}\text { Crystal } \\
\text { Phase }\end{array}$} \\
\hline & $\begin{array}{c}\text { Temp. } \\
\left({ }^{\circ} \mathrm{C}\right)\end{array}$ & $\underset{(\mathrm{hr})}{\text { Time }}$ & Sol. Nur & nber & $\underset{\left({ }^{\circ} \mathrm{C}\right)}{\text { Temp. }}$ & $\begin{array}{l}\text { Time } \\
\text { (hr) }\end{array}$ & $\begin{array}{l}\text { Temp. } \\
\text { ("C) }\end{array}$ & $\underset{(h r)}{\text { Time }}$ & & & & & \\
\hline (1) $\begin{array}{l}\text { (a) } \\
(\mathrm{b}) \\
(\mathrm{c})\end{array}$ & $\begin{array}{l}+3 \\
60 \\
85\end{array}$ & $\begin{array}{l}0 \\
0 \\
0\end{array}$ & $\begin{array}{l}\text { IPA* } \\
\text { IPA } \\
\text { IPA }\end{array}$ & $\begin{array}{l}3 \\
3 \\
3\end{array}$ & $\begin{array}{l}120 \\
120 \\
120\end{array}$ & $\begin{array}{l}24 \\
24 \\
24\end{array}$ & $\begin{array}{l}550 \\
550 \\
550\end{array}$ & $\begin{array}{l}2 \\
2 \\
2\end{array}$ & $\begin{array}{l}340 \\
295 \\
249\end{array}$ & $\begin{array}{l}0.686 \\
1.011 \\
0.850\end{array}$ & $\begin{array}{r}81 \\
137 \\
137\end{array}$ & $\begin{array}{l}32.4 \\
32.4 \\
53.9\end{array}$ & $\begin{array}{c}\text { Boehmite } \\
\text { " }\end{array}$ \\
\hline (2) $\left(\begin{array}{l}\text { (a) } \\
\text { (b) }\end{array}\right.$ & $\begin{array}{l}60 \\
60\end{array}$ & $\begin{array}{l}0 \\
5\end{array}$ & $\begin{array}{l}\text { IPA } \\
\text { IPA }\end{array}$ & $\begin{array}{l}3 \\
3\end{array}$ & $\begin{array}{l}120 \\
120\end{array}$ & $\begin{array}{l}24 \\
24\end{array}$ & $\begin{array}{l}550 \\
550\end{array}$ & $\begin{array}{l}2 \\
2\end{array}$ & $\begin{array}{l}295 \\
306\end{array}$ & $\begin{array}{l}1.011 \\
0.985\end{array}$ & $\begin{array}{l}137 \\
129\end{array}$ & $\begin{array}{l}32.4 \\
40.3\end{array}$ & $\begin{array}{l}\text { Boehmite } \\
\text { Borl. + Bay. }\end{array}$ \\
\hline (c) & 60 & 24 & IPA & 3 & 120 & 24 & 550 & 2 & 267 & 0.670 & 100 & 81.5 & $\begin{array}{l}\text { Boch. + Bay. } \\
\quad \text { (weak) }\end{array}$ \\
\hline (3) $\begin{array}{l}(\mathrm{a}) \\
(\mathrm{b}) \\
(\mathrm{c})\end{array}$ & $\begin{array}{l}+3 \\
43 \\
43\end{array}$ & $\begin{array}{l}0 \\
0 \\
0\end{array}$ & $\begin{array}{l}\text { IPA } \\
\text { IPA } \\
\text { IPA }\end{array}$ & $\begin{array}{l}3 \\
3 \\
3\end{array}$ & $\begin{array}{l}120 \\
120 \\
120\end{array}$ & $\begin{array}{r}2 \\
5 \\
24\end{array}$ & $\begin{array}{l}550 \\
550 \\
550\end{array}$ & $\begin{array}{l}2 \\
2 \\
2\end{array}$ & $\begin{array}{l}288 \\
309 \\
340\end{array}$ & $\begin{array}{l}0.822 \\
0.778 \\
0.686\end{array}$ & $\begin{array}{r}114 \\
101 \\
81\end{array}$ & $\begin{array}{l}30.0 \\
28.9 \\
32.4\end{array}$ & $\begin{array}{c}\text { Boehmite } \\
\text { " } \\
\text { " }\end{array}$ \\
\hline (4) $\begin{array}{l}\text { (a) } \\
\text { (b) } \\
(\mathrm{c})\end{array}$ & $\begin{array}{l}43 \\
43 \\
43\end{array}$ & $\begin{array}{l}0 \\
0 \\
0\end{array}$ & $\begin{array}{l}\text { Water } \\
\text { Water } \\
\text { Water }\end{array}$ & $\begin{array}{r}1 \\
3 \\
10\end{array}$ & $\begin{array}{l}120 \\
120 \\
120\end{array}$ & $\begin{array}{l}24 \\
24 \\
24\end{array}$ & $\begin{array}{l}550 \\
550 \\
550\end{array}$ & $\begin{array}{l}2 \\
2 \\
2\end{array}$ & $\begin{array}{l}270 \\
240 \\
223\end{array}$ & $\begin{array}{l}0.486 \\
0.445 \\
0.467\end{array}$ & $\begin{array}{l}72 \\
74 \\
84\end{array}$ & $\begin{array}{r}31.0 \\
35.2 \\
-\end{array}$ & $\begin{array}{l}\text { " } \\
\text { Boeh.+ Bay. } \\
\text { (weak) }\end{array}$ \\
\hline$*$ & $\begin{array}{l}\text { A: Isof } \\
\text { ristallite } \\
\text { nerrer's }\end{array}$ & tion: & $\begin{array}{l}\text { calcula } \\
D_{\mathrm{hkl}}=\end{array}$ & - & g & $0^{\circ}$ & & & $\begin{array}{l}\mathrm{D}_{\mathrm{b}} \\
\lambda: \\
\beta: \\
\theta:\end{array}$ & $\begin{array}{l}\text { mean } \\
\text { e leng } \\
\text { max } \\
\text { ractio }\end{array}$ & $\begin{array}{l}\text { mension } \\
\text { of } \mathrm{CuK} K \\
\text { um line } \\
\text { ingle }\end{array}$ & of crys & dian) \\
\hline
\end{tabular}

properties were investigated. is a result, it was found that when drying proceeded enough, specific surface area increased and pore volume decreased. This means that mean pore diameter became small. These results are supposed to occur owing to the facts that the volume of isopropylalcohol attached to the alumina hydrate decreased as the drying time became longer and the generation of pores having a large diameter was restrained, which would be mentioned later, and also the effect on the disappearance of pores of small diameter, which occurred when alumina hydrate had adsorbed water, was observed to decrease due to drying for long period of time. In order to make sure of this observation, the physical properties of alumina hydrate, which was washed in water to make it alcohol free, were measured. The results are shown on Table 1 (4). It was observed that comparing with the results on Table 1 (3), both pore volume and specific surface area decreased because of washing in water. 3.3 Effects of Calcining Conditions

To study the effects of calcining conditions on pore properties, commercial alumina hydrate (boehmite gel) was calcined at a certain temperature for a certain period of time in an electric furnace and their physical properties were measured. The results are shown on Table 2. From Table 2 (1), it was observed that as the calcining temperature was raised higher, specific surface area tended to decrease, and in constrast, pore volume increased. From the experimental results, it was supposed that as the temperature
Table 2 Effects of Calcination on Pore Propertics of Nlumina

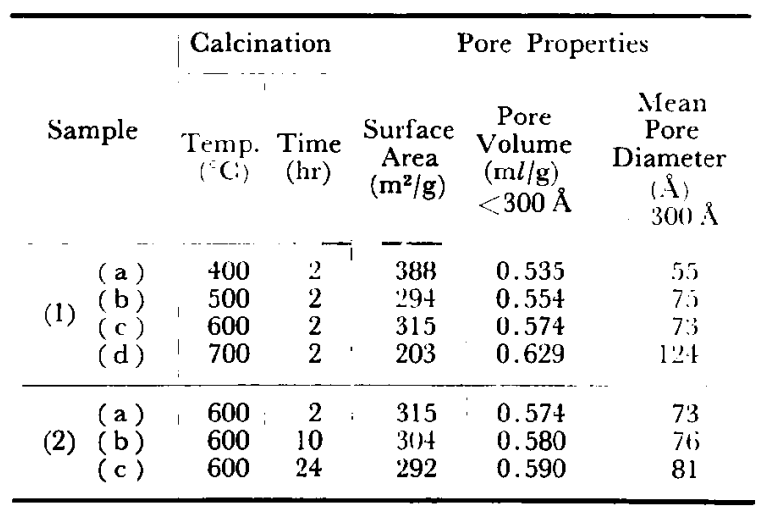

was raised higher, sintering proceeded, small pores disappeared and mean pore diameter became large. Also, the effects of calcining period at $600^{\circ} \mathrm{C}$ are shown on Table 2 (2). As the calcining period was prolonged, pore volume increased a little and specific surface area decreased. It was supposed, however, that comparing with the effects of temperature, effects of the time was relatively small.

The effects of calcining temperature on pore size distribution curve are shown on Fig. 1 and Fig. 2. Comparing with the results on Table 2, it is observed that the peak of the pore distribution curve transferred to pores of larger diameter.

\subsection{Effects of Alcohol Treatment}

Few papers had studied the controlling methods of pore size distribution of catalyst supports 


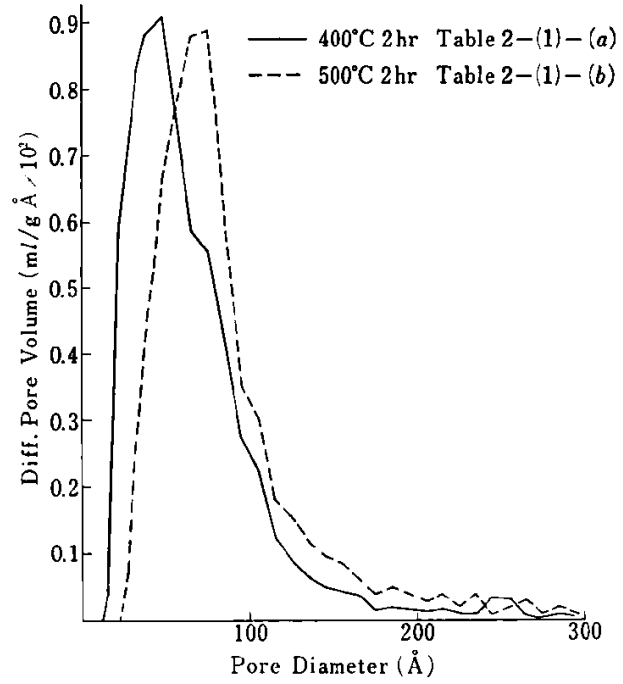

Fig. 1 Pore Size Distribution of Calcined Alumina (1)

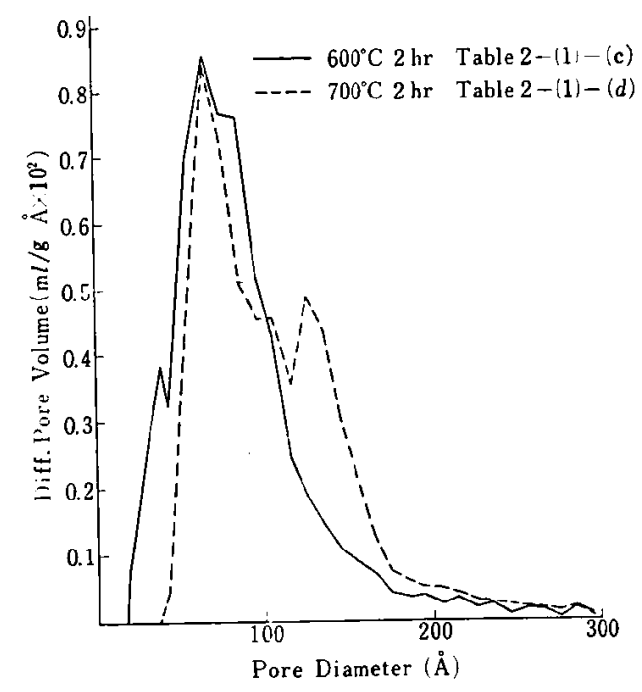

Fig. 2 Pore Size Distribution of Calcined Alumina (2)

which had micro pore under $300 \AA$ in diameter suitable for hydrodesulfurization catalyst. Also, papers on formation mechanism of pores were found to be few. The authors investigated the effects of alcohol on pore properties and their mechanism using commercial alfol alumina gel. In Table 3 and Fig. 3, changes of physical properties caused by alcohol treatment are shown. From the experimental results, the changes in pore size distribution were found according to the kinds of alcohol used. In the following experiment, the effects of some kinds of alcohol on alumina hydrates were studied. Alfol alumina hydrates have boehmite type crystallite structure, not having so good crystallinity as judged from the X-ray diffraction figures. Generally, in case of such compound of layer structure as alumina hydrates, water is

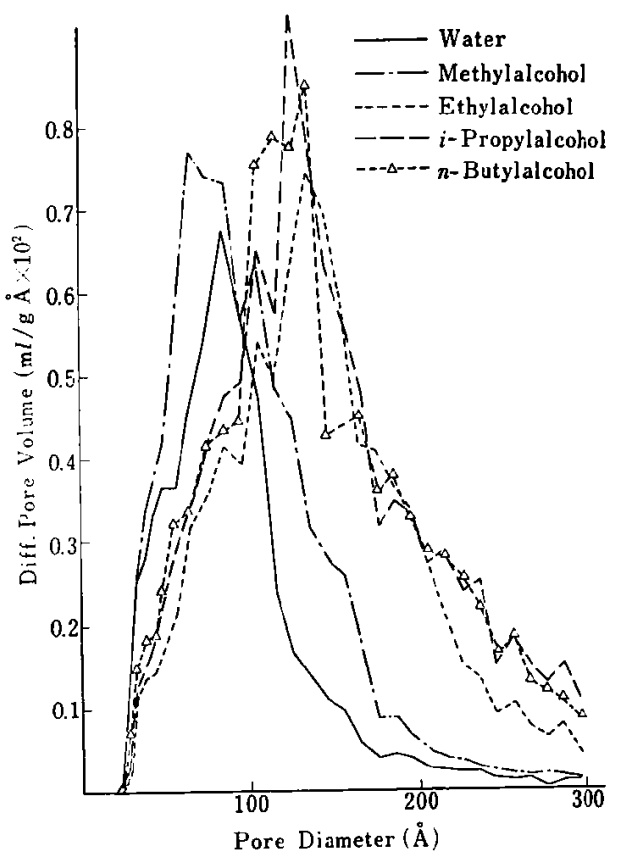

Fig. 3 Effects of Alcohol Washing on Pore Size Distribution

Table 3 Effects of Addition of Alcohols on Pore Properties of Alumina

\begin{tabular}{|c|c|c|c|c|c|}
\hline \multirow[b]{2}{*}{ Sample } & \multicolumn{2}{|c|}{ Calcination } & \multicolumn{3}{|c|}{ Pore Properties } \\
\hline & $\begin{array}{c}\text { Temp. } \\
\left({ }^{\circ} \mathrm{C}\right)\end{array}$ & $\begin{array}{c}\text { Time } \\
\text { (hr) }\end{array}$ & $\begin{array}{c}\text { Surface } \\
\text { Area } \\
\left(\mathrm{m}^{2} / \mathrm{g}\right)\end{array}$ & $\begin{array}{c}\text { Pore } \\
\text { Volume } \\
(\mathrm{m} l / \mathrm{g}) \\
<300 \AA\end{array}$ & $\begin{array}{c}\text { Mean } \\
\text { Pore } \\
\text { Diameter } \\
(\AA) \\
<300 \AA\end{array}$ \\
\hline a) Water & 550 & 2 & 220 & 0.473 & 86 \\
\hline $\begin{array}{l}\text { b) Methyl } \\
\text { Alcohol }\end{array}$ & 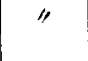 & $" 1$ & 288 & 0.685 & 95 \\
\hline $\begin{array}{l}\text { c) Ethyl } \\
\text { Alcohol }\end{array}$ & " & " & 251 & 0.852 & 136 \\
\hline 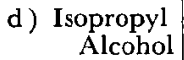 & $"$ & $"$ & 276 & 1.037 & 151 \\
\hline e) $\begin{array}{c}n \text {-Butyl } \\
\text { Alcohol }\end{array}$ & $"$ & " & 299 & 1.017 & 136 \\
\hline $\begin{array}{l}\text { f) Hexyl } \\
\text { Alcohol }\end{array}$ & " & " & 228 & 0.430 & 75 \\
\hline 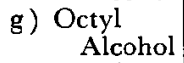 & " & " & 197 & 0.418 & 85 \\
\hline $\begin{array}{l}\text { h) Decyl } \\
\text { Alcohol }\end{array}$ & " & $1 "$ & 202 & 0.451 & 89 \\
\hline
\end{tabular}

included between layers which is combined comparatively loosely in van der Waals bond. Also, it is known that this water is easily substituted by such polar organic compound as amine group, alcohol group, glycol group, etc.. The results of measurement of alfol alumina hydrates by the differential thermo balance are shown in Fig. 4. From this figure. two endothermic peaks were noticed; the first one was from normal temperature to $240^{\circ} \mathrm{C}$ and the second one was from $350^{\circ} \mathrm{C}$ to $530^{\circ} \mathrm{C}$. The decreased volume at this time was calculated to be $2.06 \mathrm{~mol} \mathrm{H}_{2} \mathrm{O}$ per $\mathrm{Al}_{2} \mathrm{O}_{3} 1 \mathrm{~mol}$ as crystal water. From Fig. 5, 


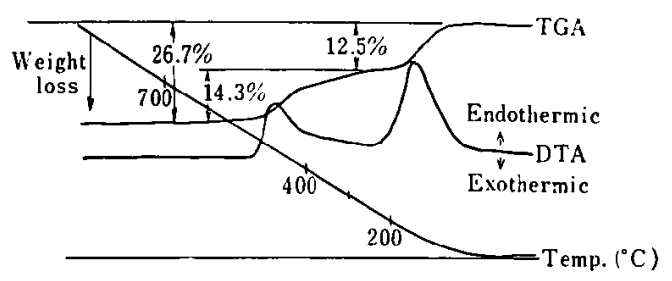

TGA: Thermogravimetric analysis DTA: Differential thermal analysis

Fig. 4 Derivatogram of Boehmite Gel

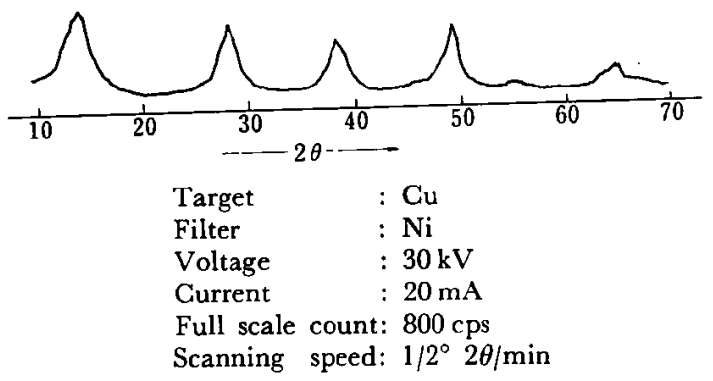

Fig. 5 X-Ray Diffraction of Boehmite Gel

the value of inter planar spacing $d_{020}$ was obtained as $6.23 \AA$. According to Lippens ${ }^{4}$ report on the relationship between an inter planar spacing $\mathrm{d}_{020}$ and number of mol of crystal water, when the value of crystal water was $1.21 \mathrm{~mol}$, the inter planar spacing $\mathbf{d}_{020}$ was $6.23 \AA$. Therefore, the water of $2.06 \mathrm{~mol}$ which was obtained in this study was supposed to include the adsorbed water besides the crystal water.

Judging from the two endothermic peaks in the differential thermo balance, existence of two kinds of water having clearly different combining powers was recognized. From these experimental results it was considered that in the alfol alumina hydrates, the first peak was the normal adsorbed water and the second one was the crystal water of $1.1 \mathrm{~mol} \mathrm{H}_{2} \mathrm{O}$ on measurement; that is, adsorbed water between layers. The size of the crystallite of the $(020)$ reflection of boehmite was measured to be $27 \AA$. When this boehmite was added alcohol, the alcohol was considered to permeate into the following three kinds of interstice; among layers of the layer structure, among crystallites and among aggregates. At first among layers, no more than $1.1 \mathrm{~mol}$ of water from the differential thermo balance, and $1.2 \mathrm{~mol}$ of water from the X-ray diffraction was found. Therefore, it was supposed that the substitution by permeation was difficult. Indeed, very small changes were ascertained in an inter planar spacing $\mathrm{d}_{020}$ by X-ray difraction after alcohol was added. As Johnson? mentioned, pores formed by dehydration of water among layers of boehmite were such small as could not be checked by measure- ment of pore size distribution by the adsorption isotherm of $\mathrm{N}_{2}$. Also, summation of specific surface area calculated from pore size distribution agreed well with that measured using the BET Method and very small pores, namely pores having a diameter less than $20 \AA$ were never found after alcohol was added (Fig. 3). From the above observations, it was supposed that in this study the permeation of alcohol into interstice among layers did not occur by the alcohol treatment of boehmite. Next, alcohol seemed to permeate into interstice among crystallite and into interstice among particles which were formed owing to agrigation of crystallites. In the latter case, interstice among particles was considered relatively wide, namely an average size of particle agrigated was about $40 \mu$. Therefore essential effects on pore size distribution of pores having diameter from 0 to $300 \AA$ were supposed to occur by the alcohol permeation into interstice among crystallites.

Boehmite, after impregnated in Methylalcohol, Ethylalcohol, Isopropylalcohol and n-Butylalcohol respectively, was dried for 24 hours at $120^{\circ} \mathrm{C}$, calcined for 2 hours at $550^{\circ} \mathrm{C}$ and its pore properties were measured by means of the adsorption isotherm of $\mathrm{N}_{2}$. The results are shown in Fig. 3 and Table 3. As seen in the figure and in the table, an increase in comparatively large pores was observed in the boehmite impregnated in Methylalcohol and while in the boehmite which was impregnated in Isopropylalcohol and $n$-Butylalcohol, an increase in large pores was found very remarkably. In consequence, pore volume and mean pore diameter became large and also specific surface area increased though not so much as pore volume. The reasons of these results are considered as follows: boehmite was dried and calcined, including alcohol among crystallites as mentioned before and contraction by surface tension of water and dessolution and subsequently crystallization of alumina hydrates to water vapour took place repeatedly during the calcination period. In other words, alcohol has the promotion effects on calcining crystallites; therefore the decrease in pore volume was supposed to be prevented by the alcohol. When the alcohols of rather large molecular weight were used, the pore volume was observed to become a little large. However, as seen in Table 3, when such alcohols abundant in carbon number as Hexylalcohol, Octylalcohol and Decylalcohol were used, the permeation of molecules did not take place easily and the effects on pore structure of alcohol were not observed.

\subsection{Effects of Acid}

To $100 \mathrm{~g}$ of alfol alumina hydrates dried at 
120 ( 1 was added separately the following nitric acid solution a) no addition, b) $3.2 \times 10^{-3}$ mol, c) $5.2 \times 10^{-2} \mathrm{~mol}$, d) $2.5 \times 10^{-1} \mathrm{~mol}$, c) $7.4 \times 10^{-1} \mathrm{~mol}$. The mixture was kneaded well, dried at $120 \mathrm{C}$ : for 5 hours and then calcined at 600 (: for 5 hours. The physical properties of thus prepared samples are shown in Table 4 and Fig. 6. Independent of the volume of acid added, pore volume and also mean pore diameter decreased greatly, though specific surface area was almost constant. These results were supposedly caused by the way the surface of alumina dissolved by acid little by little, which had effects to bind alumina particles and after all, to plug the pores. However, acid acted on pores larger than $50 \AA$ in diameter and did not permeate into smaller pores and therefore it was assumed that the specific surface area was not changed by acid.

\section{Conclusion}

1) With higher the hydrolysis temperature, the crystallites became larger from $32.4 \hat{X}$ to

Table 4 Effect of Nitric Acid on Pore Properties

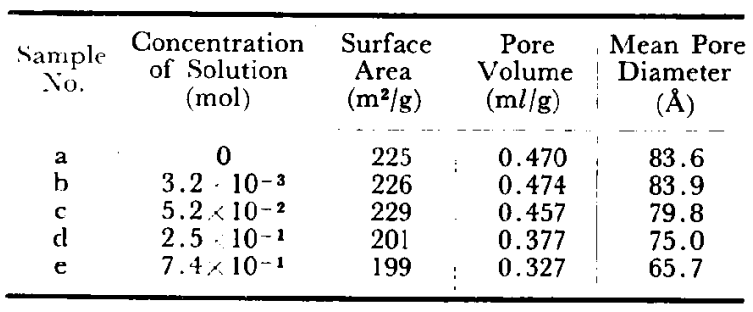

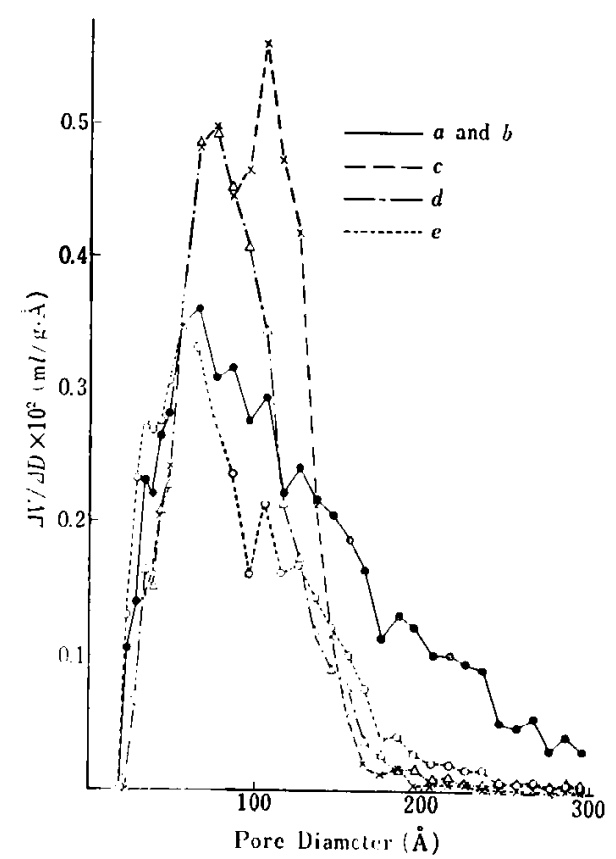

Fig. 6 Effect of Acid on Pore Properties
$53.9 \AA$ in diameter, the specific surface area decreased from $340 \mathrm{~m}^{2} / \mathrm{g}$ to $249 \mathrm{~m}^{2} / \mathrm{g}$ and the pore volume of the pores having diameter less than $600 \AA$ increased. When aging period of boehmite gel was prolonged, the degree of crystallinity advanced along with the crystal growth of bayerite and consequently, the specific surface area and the pore volume decreased.

2) When the alumina hydrates were washed in water, pore volume and specific surface area decreased. When they were washed in such particular alcohol as Methylalcohol, Ethylalcohol, Isopropylalcohol and $n$-Butylalcohol, the pore volume and the specific surface area increased on the contrary.

3) As the calcination temperature was raised higher, the specific surface area decreased rapidly and in reverse, the pore volume increased. 4) The most important effect on the pore structure of the alumina as catalyst support was the permeation of alcohols into the interstice of crystallites of alumina. Also, selecting the preparation conditions of alumina hydrates adequately, the diameter of crystallites could be changed markedly and, consequently, the pore structure could be controlled.

5) When nitric acid was added to alumina hydrates and they were calcined to make alumina supports, the spccific surface area was constant independent of the acid concentration, while the pore volume and the mean pore diameter decreased according to increase of the acid concentration.

\section{Acknowledgement}

In conclusion, we express our cordial thanks to Dr. T. Shiba, Honorary Professor of Tokyo Institute of Technology and Dr. M. Mitarai, Central Laboratory of Sumitomo Mining Co., for their guidance in our study, and also to $\mathrm{Mr}$. Ogata of Agency of Industrial Science \& Technology, M. I. T. I. for the cooperation extended to us throughout our study.

\section{References}

1) Inoguchi, M., Nishiyama, R. et al,, Bull. Japan Petrol. Inst., 13, 3 (1971).

2) Inoguchi, M., Inaba, K. et al., ibid., 13, 11 (1971).

3) Inoguchi, M., Mizutori, T. et al., ibid., 13, 19 (1971).

4) Lippens, B. C., Physical and Chemical Aspects of Adsorbents and Catalysts, Chapter 4, 171 (1970). Academic Press.

5) De Boer, J. H., Lippens, B. C., J. Catalysis, 3, 38 (1964).

6) Lippens, B. (.., De Bocr, J. H., idid., 3, 44 (1964).

7) Johnson, M. F. L., Mori. ibid., 10, 342 (1968).

8) Crauston, R. W.. Inklcy, F. A., .1dl. Catalysis, 9, $143(1957)$. 